\title{
In Vitro Steroidogenesis on Oocyte Development in the Starry Flounder, Platichthys stellatus
}

\author{
${ }^{\dagger}$ Hea Ja Baek ${ }^{1}$, Dea Geun Kim ${ }^{1}$ and Hyung Bae Kim ${ }^{2}$ \\ ${ }^{1}$ Department of Marine Biology, Pukyong National University, Busan 608-737, Republic of Korea \\ ${ }^{2}$ Department of Marine Bio-Resources, Gangwon Provincial University, Gangnung 210-804, Republic of Korea
}

\begin{abstract}
In this study, oocyte steroidogenesis are investigated in relation to oocyte development in the starry flounder, Platichthys stellatus, a marine multiple spawner. Vitellogenic (0.52 and $0.55 \mathrm{~mm}$ oocyte diameter) and mature oocytes (0.63, 0.66 and $0.71 \mathrm{~mm}$ oocyte diameter) were incubated in vitro in the presence of $\left[{ }^{3} \mathrm{H}\right] 17 \alpha$-hydroxyprogesterone $\left(\left[{ }^{3} \mathrm{H}\right] 17 \alpha\right.$ OHP) as a precursor. Steroid metabolites were extracted from the incubated media and oocytes, the extracts were separated and identified by thin-layer chromatography (TLC), high performance liquid chromatography (HPLC) and gas chromatographymass spectrometry (GC-MS). The major metabolites produced from $\left[{ }^{3} \mathrm{H}\right] 17 \alpha-\mathrm{OHP}$ were androgens [androstenedione $\left(\mathrm{A}_{4}\right)$ and testosterone $(\mathrm{T})]$ and estrogens [17 $\beta$-estradiol $\left(\mathrm{E}_{2}\right)$ and estrone $\left.\left(\mathrm{E}_{1}\right)\right]$ and progestins [17 $\alpha, 20 \alpha$-dihydroxy-4-pregnen-

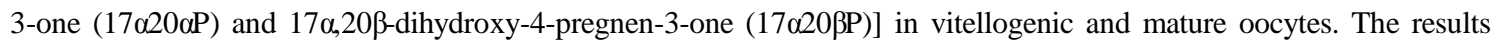
from this study suggest the potential roles of $\mathrm{E}_{1}$ in the oocytes with diameter $0.52-0.71 \mathrm{~mm}, 17 \alpha 20 \alpha \mathrm{P}$ and $17020 \beta \mathrm{P}$ at the oocytes of $0.63,0.66$ and $0.71 \mathrm{~mm}$.
\end{abstract}

Key words : Starry flounder, Maturation inducing steroid, Steroid metabolite, Oocyte maturation, vitellogenesis

\section{INTRODUCTION}

Oocyte developmental process in teleosts is under the influence of sex steroid hormone that is generated from the follicle layer, and the sex hormone is regulated by the pituitary gonadotropin (GtH) (Nagahama et al., 1994; Planas \& Swanson, 2008). In female fish, estradiol-17 $\beta$ $\left(\mathrm{E}_{2}\right)$, testosterone $(\mathrm{T})$ and progestins are the main gonadal steroids. During vitellogenesis, E2 is the major sex steroid, synthesized at follicle cell layer and transported to liver. Then stimulated liver produced vitellogenin, the precursor of yolk protein. After vitellogenesis, progestins such as 17 $\alpha, 20 \beta$-dihydroxy-4-pregnen-3-one (17 $\alpha 20 \beta \mathrm{P})$ and/or $17 \alpha, 20 \beta, 21$-trihydroxy-4-pregnen-3-one (17 $\alpha 20 \beta 21 \mathrm{P})$ act as maturation inducing steroid (MIS) and induce final oocyte maturation including germinal vesicle breakdown (GVBD) and ovulation (Patiño \& Sullivan, 2002; Baek, 2008; Nagahama \& Yamashita, 2008). Androgens, T and 11-ketotestosterone (11-KT), are generally considered playing a role in regulating testis differentiation and spermatogenesis (Borg, 1994). However, it was reported in several species of fish including those of the Anguillidae family, that 11-KT was also identified as the major androgens in the blood of females (Lokman et al., 2002; Setiawan et al., 2012). The role of these sex steroids in fish reproductive process is still unclear, due to the high diversity of reproductive strategies. This may be different in fish species with synchronous or asynchronous ovarian development

\footnotetext{
Manuscript received 27 November 2013, Received in revised form 17 December 2013, Accepted 23 December 2013

${ }^{\dagger}$ Corresponding Author : Hea Ja Baek, Department of Marine Biology, Pukyong National University, Busan 608-737, Republic of Korea. Tel. : +82-51-629-5924, Fax : +82-51-629-5931, E-mail : hjbaek@pknu.ac.kr

This is an Open Access article distributed under the terms of the Creative Commons Attribution Non-Commercial License(http://creativecommons. org/licenses/by-nc/3.0) which permits unrestricted non-commercial use, distribution, and reproduction in any medium, provided the original work is properly cited.
} 
(Tyler \& Sumpter, 1996).

The starry flounder (Platichthys stellatus), which is a regional specific species in East Sea of Korea, exhibits multiple spawning and asynchronous ovarian development (Lim et al., 2007; Hwang et al., 2012). Since it is getting hard to catching the natural starry flounder, we are planning to recover fisheries resource and increase fisheries stocks by releasing artificial fish seed; however, few studies have investigated concerning its reproductive characteristics. Understanding steroidogenesis in starry flounder could elucidate the endocrine control of reproductive cycle. Therefore, in this study, we analyzed in vitro oocyte steroidogenesis and identified steroid metabolites from vitellogenic and post-vitellogenic stages (mature oocytes) of development in the starry flounder.

\section{MATERIALS AND MATHODS}

\section{Experimental fish and oocyte incubation in vitro}

The starry flounder used in this study were captured in coastal waters of Pohang, Korea during the breeding season (December-March). Oocytes were separated into groups using fine forceps. Oocytes with average diameters of 0.52-0.71 mm were used for incubation. After separating the ovaries into small pieces in ice-cold balanced salt solution (132.96 mM NaCl, $3.09 \mathrm{mM} \mathrm{KCl,} 0.28 \mathrm{mM}$ $\mathrm{MgSO}_{4} \cdot 7 \mathrm{H}_{2} \mathrm{O}, 0.98 \mathrm{mM} \mathrm{MgCl}_{2} \cdot 6 \mathrm{H}_{2} \mathrm{O}, 3.40 \mathrm{mM} \mathrm{CaCl} 2$ . $6 \mathrm{H}_{2} \mathrm{O}$, and $3.65 \mathrm{mM}$ HEPES), approximately 30 follicleenclosed oocytes were incubated in the presence of 55 $\mathrm{kBq}$ of $\left[{ }^{3} \mathrm{H}\right]-17 \alpha \mathrm{OHP}$ as the radiolabeled precursor in each well of 24-well culture plates containing $1 \mathrm{ml}$ of Leibovitz L15 medium (Gibco). The $\mathrm{pH}$ and osmolarity of the media were adjusted to 7.9 and 300 mOsm, respectively. The plates were incubated for $24 \mathrm{~h}$ at $12^{\circ} \mathrm{C}$ with constant gentle shaking. Some pieces of ovary from each individual were fixed in Bouin's solution for 24 hours for histological observations of oocytes. The fixed samples were washed, dehydrated, and embedded in paraffin. Serial sections of 4-6 $\mu \mathrm{m}$ thickness were prepared; the slides were stained in Mayer's hematoxylin and $0.5 \%$ eosin and mounted with malinol.
Histological samples were observed through a light microscope (BX50, Olympus, Japan).

\section{Steroid extraction and analysis of steroid metabolism}

At the end of the incubation, steroids were extracted three times from the media and oocytes using $4 \mathrm{ml}$ dichloromethane. The extracts were concentrated and applied to a thin-layer chromatography (TLC) plate (60F254; Merck, Darmstadt, Germany) with non-radioactive standard steroids as carrier steroids, and developed in a mixture of benzene: acetone (4:1) and benzene: ethyl acetate (4:1). Radioactive steroid metabolites were analyzed using a BAS 1500 bio-imaging analyzer (Fuji Film, Tokyo, Japan), and estrone (E1) and E2 standards were visualized by exposure to iodine vapor. Other standard steroids were detected by UV absorption at $254 \mathrm{~nm}$.

The migration zones corresponding to the carrier steroids were eluted twice from the silica plate bands with $5 \mathrm{ml}$ of dichloromethane: methanol (90:10). Following centrifugation at $1,000 \times \mathrm{g}$ for $10 \mathrm{~min}$, the supernatants were vacuum dried before finally being dissolved in $20 \mu \mathrm{l}$ of acetonitrile. Extracts were then analyzed by reverse-phase high-performance liquid chromatography (HPLC). Briefly, a Waters Alliance HPLC system (Waters, Milford, MA, USA) equipped with a binary pump (515 HPLC pump, Waters) and UV detector (2487 multi-wavelength absorbance detector, Waters) was used. Chromatographic separation was performed on a Sunfire C18 analytical column $(4.6 \times 150-\mathrm{mm}$ I.D., 3.5- $\mu \mathrm{m}$ particle size; Waters Sunfire). The flow rate and mobile phase were $0.6 \mathrm{ml} / \mathrm{min}$ with $20 \%$ methanol and $0.4 \mathrm{ml} / \mathrm{min}$ with absolute acetonitrile.

The steroid metabolites were identified by gas chromatograpumass spectrometry (GC-MS). Steroids were analyzed on a DB-5MS column ( $60 \mathrm{~m} \times 0.25 \mathrm{~mm}$ O.D. $\times 0.25 \mu \mathrm{m}$ I.D.) using a Shimadzu GCMS-QP2010 mass spectrometer interfaced to GC-2010 gas chromatograph. The following conditions were used: splitless injection at $80^{\circ} \mathrm{C}$ (injector temperature of $280^{\circ} \mathrm{C}$ ), followed by a 1-min delay before maximal temperature $20^{\circ} \mathrm{C} / \mathrm{min}$ to program starting temperature of $250^{\circ} \mathrm{C}$. Thereafter, the temperature was programmed at 
$5^{\circ} \mathrm{C} /$ min to maximum $295^{\circ} \mathrm{C}$.

\section{RESULTS}

\section{Histological observation of oocytes}

Histological analysis of fish ovary was performed using the samples, collected at five each sampling during the breeding season (January to February). In both the 0.52 and $0.55 \mathrm{~mm}$ diameter oocytes of starry flounder, yolk granules were spread throughout the ooplasm, and nucleus (N) was located near the center of oocytes (Fig. 1A and B). In 0.63 and $0.66 \mathrm{~mm}$ diameter oocytes of starry flounder, migration of $\mathrm{N}$ was observed (Fig. 1C and D). Later, nucleus was gradually displaced toward the animal pole in $0.71 \mathrm{~mm}$ diameter oocytes of starry flounder; yolk granules were increased and combined together (Fig. 1E).

\section{Steroid matabolism}

When vitellogenic oocytes ( 0.52 and $0.55 \mathrm{~mm}$ in diameter) were incubated with $\left[{ }^{3} \mathrm{H}\right]-17 \alpha \mathrm{P}$, the four major separated metabolites were A4, T, E1 and E2 (Fig. 2); E2 and 170P were overlapped slightly by TLC, and $\mathrm{E}_{2}$ was further identified by HPLC. In 0.63, 0.66 and $0.71 \mathrm{~mm}$ diameter oocytes of starry flounder, undergoing germinal vesicle migration, unknown metabolites (?, predicted to progestin) between $17 \alpha 20 \beta \mathrm{P}$ and $17 \alpha 20 \alpha \mathrm{P}$ were also detected.

Moreover, the presence of a small quantity of estrogens was observed in the oocytes of $0.71 \mathrm{~mm}$. The five zones of metabolites (converted from $\left[{ }^{3} \mathrm{H}\right]-17 \alpha \mathrm{P}$ using the oocytes of $0.52-0.71 \mathrm{~mm}$ ) corresponding to the carrier steroid in TLC were eluted and identified by HPLC (data not shown). From the oocytes of 0.63 and $0.66 \mathrm{~mm}$ it looks like there were two separated spots of $\mathrm{A}_{4}$, but it turned out be only the presence of A4. The GC-MS analysis was performed for the identification of $17 \alpha 20 \beta P, 17 \alpha$ 200P and E1 (Fig. 3). The GC-MS analysis of unknown metabolites (?) in the oocytes of $0.63,0.66$ and $0.71 \mathrm{~mm}$ revealed the presence of $17 \alpha 20 \beta \mathrm{P}$ and $17 \alpha 20 \alpha \mathrm{P}$.

\section{DISCUSSIONS}

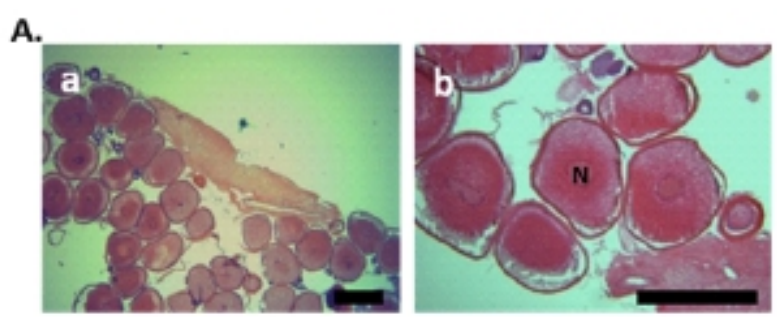

B.

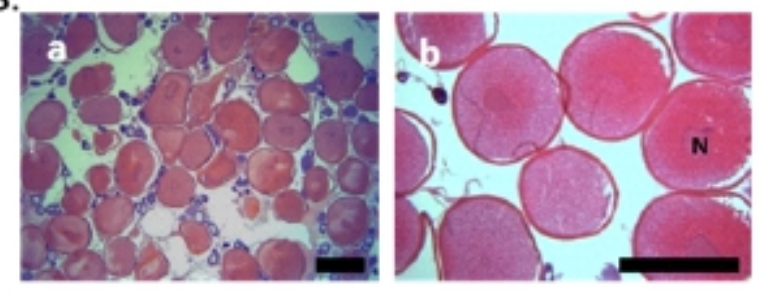

C.
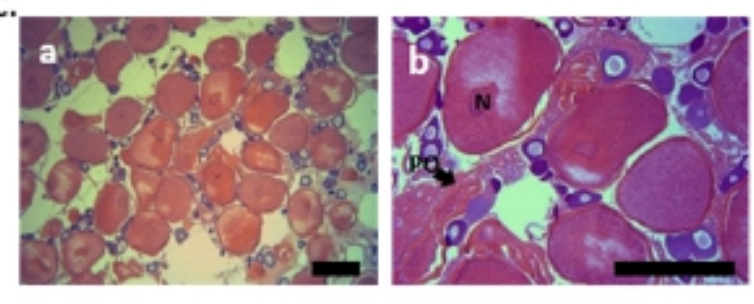

D.
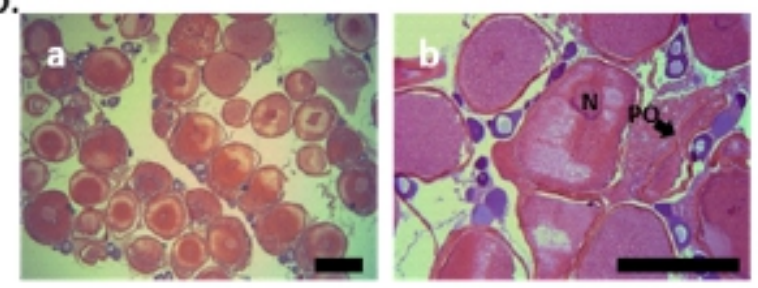

E.
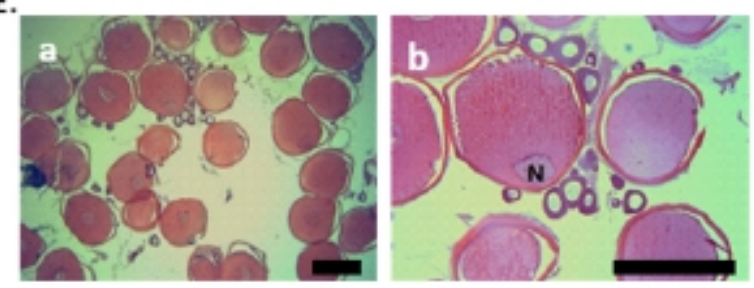

Fig. 1. Histological observation of ovary in stany flouder, Platichthys stellatus. A, Ovary with oocytes of $0.52 \mathrm{~mm}$ diameter; B, Ovary with oocytes of $0.55 \mathrm{~mm}$ diameter; C, Ovary with oocytes of $0.63 \mathrm{~mm}$ diameter; D, Ovary with oocytes of $0.66 \mathrm{~mm}$ diameter; E, Ovary with oocytes of $0.71 \mathrm{~mm}$ diameter. a: 40×, b:100×. Scale bar 500um. N, nucleus; $\mathrm{PO}$, post ovulatory follicles.

Steroid hormones play important roles in the reproduction of vertebrates. In fish, steroid hormones are critical to maintain hypothalamus-pituitary-gonad axis function, and feedback controls on the system are achieved largely through alterations in steroid production (Ankley et al., 2009). In 


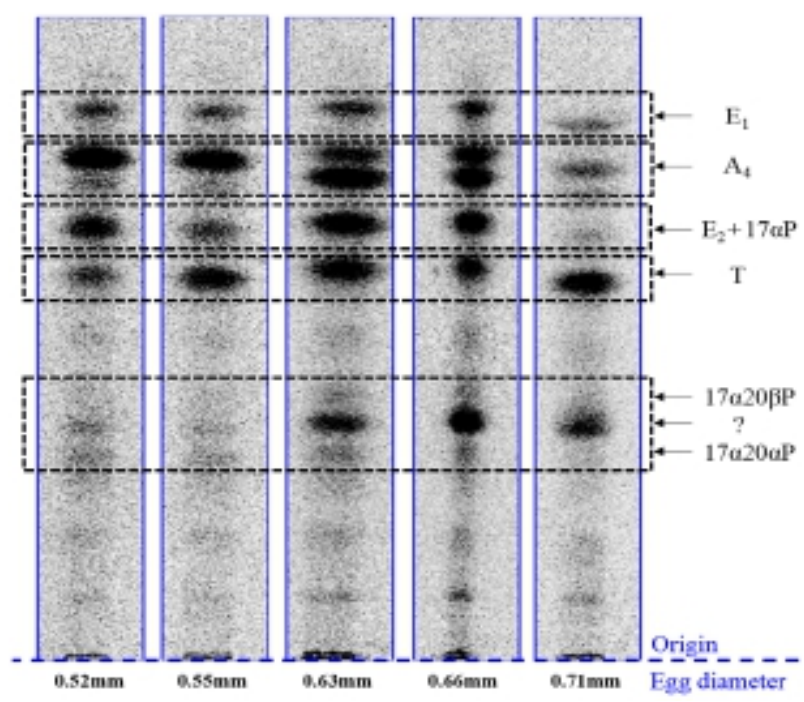

Fig. 2. Autoradiograms of steroid metabolites produced from $\left[{ }^{3} \mathrm{H}\right] 17 \alpha$-hydroxyprogesterone after $\mathbf{2 4}$ hrs incubation with isolated oocytes from starry flounder. Steroid metabolites from radiolabeled precursor were separated by thin layer chromatography developed with a benzene:acetone (4:1) and benzene:ethyl acetate (4:1) solvent system. Androstenedione $\left(\mathrm{A}_{4}\right)$, testosterone $(\mathrm{T})$, estrone $\left(\mathrm{E}_{1}\right)$, estradiol-17 $\beta\left(\mathrm{E}_{2}\right)$, $17 \alpha, 20 \beta$-dihydroxy-4-pregnen-3-one (17 $\alpha 20 \beta \mathrm{P}), 17 \alpha$,

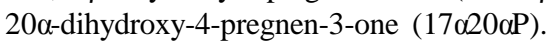

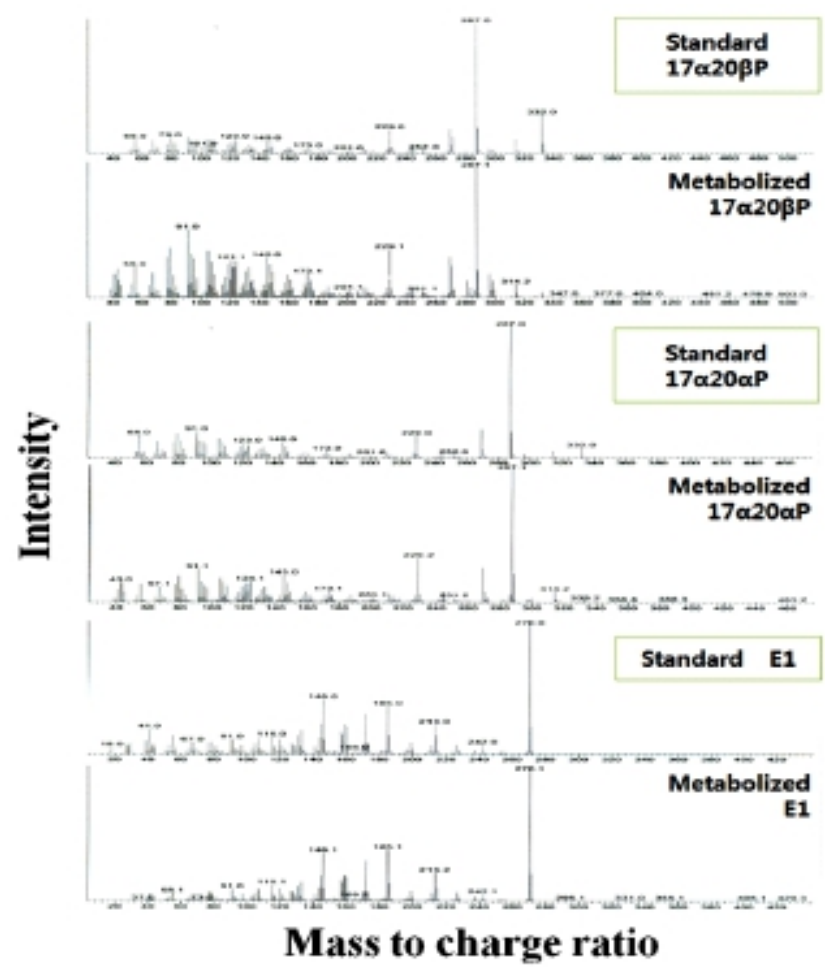

Fig. 3. Mass spectra of steroid metabolized by starry flounder oocytes identified as $17 \alpha, 20 \beta$-dihydroxy-4-pregnen-3one $(17 \alpha 20 \beta P), 17 \alpha, 20 \alpha$-dihydroxy-4-pregnen-3-one $(17020 \propto \mathrm{P})$ and estrone (E1). female fish, estradiol-17 $\beta\left(E_{2}\right)$, testosterone $(T)$ and progestins are the main gonadal steroids. E2 is the major sex steroid during vitellogenesis, and progestin such as $17 \alpha 20 \beta \mathrm{P}$ and $17 \alpha 20 \beta 21 \mathrm{P}$ is important during oocyte final maturation leading to GVBD (Patiño \& Sullivan, 2002; Baek, 2008; Nagahama \& Yamashita, 2008).

In the present study, we verified the steroid metabolites from vitellogenic ( 0.52 and $0.55 \mathrm{~mm}$ in diameter) and mature oocytes (0.63, 0.66 and $0.71 \mathrm{~mm}$ oocyte diameter) with $\left[{ }^{3} \mathrm{H}\right]-17 \alpha \mathrm{P}$ as a precursor. The major metabolites produced from the oocytes of starry flounder were $\mathrm{A}_{4}, \mathrm{~T}, \mathrm{E} 2, \mathrm{E} 1$, $17 \alpha 20 \beta \mathrm{P}$ and $17 \alpha 20 \alpha \mathrm{P}$. From these steroids, we were interested in $\mathrm{E}_{1}$ and $17 \alpha 20 \alpha \mathrm{P}$.

In the most of species, the main estrogen is $\mathrm{E}_{2}$, but vitellogenic oocytes of starry flounder also synthesized E1 as a major steroid metabolite. This metabolite was produced high through the entire period of maturation. From just prior to GVBD (in the oocytes of $0.71 \mathrm{~mm}$ ), trace amounts of estrogens was detected. E1 has about one fifth activity of $\mathrm{E}_{2}$ in inducing trout vitellogenin synthesis (Routledge et al., 1998). Similarly, Specker \& Sullivan (1994) reported that E1 may have a minor vitellogenic role in some species. In red seabream, in vitro conversion of $\mathrm{E}_{1}$ into $\mathrm{E}_{2}$ was 16-fold greater than $\mathrm{T}$ conversion into $\mathrm{E}_{2}$, suggesting that $\mathrm{E}_{2}$ is synthesized mainly via E1 rather than through T (Ohta et al., 2002). The steroidogenic pathways for estrogen production are different among species. Further studies should be performed physiological roles for intermediate products other than $\mathrm{T}$ in the E2 synthetic pathway.

When starry flounder oocytes (0.63, 0.66 and $0.71 \mathrm{~mm}$ oocyte diameter) were incubated with $\left[{ }^{3} \mathrm{H}\right]-17 \alpha \mathrm{P}$, two additional metabolites were appeared, $17 \alpha 20 \beta \mathrm{P}$ and 17 $\alpha 20 \alpha \mathrm{P}$. The activity of $17 \alpha 20 \alpha \mathrm{P}$, an isomer of $17 \alpha$ $20 \beta \mathrm{P}$, was higher than $17 \alpha 20 \beta \mathrm{P}$ in the migratory oocytes (data not shown). But $17 \alpha 20 \beta 21 \mathrm{P}$ was not detected. In this species, two progestins, $17 \alpha 20 \beta \mathrm{P}$ and $17 \alpha 20 \alpha \mathrm{P}$, likely act as MIS.

A large amount of $17 \alpha 20 \alpha \mathrm{P}$ has been found in the blood and ovarian incubates of mature flatfish species 
(Canario \& Scott, 1990; Scott \& Canario, 1990), and cyprinids (Kime et al., 1992). These authors suggested that it is not a potent inducer of oocyte maturation. The role of this steroid is still unknown.

Until now, there are two major MIS identified in fish, $17 \alpha 20 \beta \mathrm{P}$ and $17 \alpha 20 \beta 21 \mathrm{P}$. They both probably act as MIS in most fishes, but normally one of them is the predominant MIS for a given species. The $17 \alpha 20 \beta \mathrm{P}$ is the major MIS in several salmonid and non salmonid species, while $17 \alpha 20 \beta 21 \mathrm{P}$ is the major MIS in Atlantic croaker, spotted sea trout, striped bass and black porgy (Yueh et al., 2005).

Data presented in this study suggest that metabolite 17 $\alpha 20 \alpha \mathrm{P}$ may have some roles during oocyte maturation process.

\section{ACK NOWLEDGEMENTS}

This work was supported by a Research Grant of Pukyong National University (2013 year: C-D-2013-0336).

\section{REFERENCES}

Ankley GT, Bencic D, Breen M, Collette TW, Connolly R, Denslow ND, Edwards S, Ekman DR, Jensen KM, Lazorchak J, Martinovic D, Miller DH, Perkins EJ, Orlando EF, Garcia-Reyero N, Villeneuve DL, Wang RL, Watanabe K (2009) Endocrine disrupting chemicals in fish: Developing exposure indicators and predictive models of effects based on mechanisms of action. Aquat Toxicol 92:168-178.

Baek HJ (2008) Production of C21-steroids in longchin goby, Chasmichthys dolichognathus during oocyte maturation. Dev Reprod 12:107-112.

Borg B (1994) Androgens in teleost fishes. Comp Biochem Physiol 109:219-245.

Canario AVM, Scott AP (1990) Plasma levels of ovarian steroids, including 17 $20 \alpha$-dihydroxy-4-pregnen-3one and $3 \beta, 17 \alpha, 20 \beta$-trihydroxy-5 $\beta$-pregnane, in female dabs (Limanda limanda)-marine flatfish-induced to mature and ovulate with human chorionic gonadotropin. Gen Comp Endocrinol 77:177-191.

Hwang IJ, Lee JB, Choi SJ, Kim SK, Cha HK, Oh TY, Baek HJ (2012) Reproductive capacity in starry flounder Platichthys stellatus from Uljin marine ranching area, Korea. Kor J Fish Aquat Sci 45:253-261.

Kime DE, Scott AP, Canario AVM (1992) In vitro biosynthesis of steroids, including 11-deoxycortisol and $5 \alpha$-pregnane-3 $\beta, 7 \alpha, 17,20 \beta$-tetrol, by ovaries of the goldfish Carassius auratus during the stage of oocyte final maturation. Gen Comp Endocrinol 87:375-384.

Lim HK, Byun SK, Lee JH, Park SU, Kim YC (2007) Sexual maturity and reproductive cycle of starry flounder Platichthys stellatus cultured in indoor tank. J Aquacult 20:212-218.

Lokman PM, Harris B, Kusakabe M, Kime DE, Schulz RW, Adachi S, Young G (2002) 11-oxygenated androgens in female teleosts: prevalence, abundance, and life history implications. Gen Comp Endocrinol 129:1-12. Nagahama Y, Yoshikuni M, Yamashita M, Tanaka M (1994) Regulation of oocyte maturation in fish. In: Sherwood NM \& CL Hew (ed.), Fish Physiology. V13. Molecular Endocrinology of Fish. Academic Press, London, pp 393-439.

Nagahama Y, Yamashita M (2008) Regulation of oocyte maturation in fish. Develop Growth Differ 50:S195S219.

Ohta K, Yamaguchi S, Yamaguchi A, Gen K, Okuzawa K, Kagawa H, Matsuyama M (2002) Biosynthesis of estradiol-17 $\beta$ in the ovarian follicles of the red seabream, Pagrus major during vitellogenesis. Fisheries Science 68:680-687.

Patiño R, Sullivan CV (2002) Ovarian follicle growth, maturation, and ovulation in teleost fish. Fish Physiol Biochem 26:57-70.

Planas JV, Swanson P (2008) Physiological function of gonadotropins in fish. In: Rocha MJ, Arukwe A, Kapoor BG (Eds.), Fish Reproduction. Enfield (NH), Jersey, Plymouth: Science Publishers, pp 37-66.

Routledge EJ, Sheahan DD, Desbrow CC, Brighty GC, 
Waldock MM, Sumpter JP (1998) Identification of estrogenic chemicals in STW effluent. 2. In vivo responses in trout and roach. Environ Sci Technol 32:1559-1565.

Scott AP, Canario AVM (1990) Plasma levels of ovarian steroids, including 17 $\alpha, 21$-dihydroxy-4-pregnene-3,20dione (11-deoxycortisol) and 3 $3,17 \alpha, 21$-trihydroxy$5 \beta$-pregnan-20-one, in female plaice (Pleuronnectes platessa) induced to mature with human chorionic gonadotropin. Gen Comp Endocrinol 78:286-298.

Setiawan AN, Ozaki Y, Shoae A, Kazeto Y, Lokman PM (2012) Androgen-specific regulation of FSH signaling in the previtellogenic ovary and pituitary of the New Zealand shortfinned eel, Anguilla australis. Gen Comp
Endocrinol 176:132-143.

Specker JL, Sullivan CV (1994) Vitellogenesis in fishes: status and perspectives. In: Davey KG, Peter RE, Tobe SS (eds.) Perspectives in Comparative Endocrinology. National Research Council of Canada, Ottawa, pp 304-315.

Tyler CR, Sumpter JP (1996) Oocyte growth and development in teleosts. Rev Fish Biol Fish 6:287-318.

Yueh WS, Thomas P, Chang CF (2005) Identification of 17,20beta,21-trihydroxy-4-pregnen-3-one as an oocyte maturation-inducing steroid in black porgy, Acanthopagrus schlegeli. Gen Comp Endocrinol 140:184-191. 